\title{
Heat shock proteins Hsp27 and Hsp32 localize to synaptic sites in the rat cerebellum following hyperthermia
}

\author{
David A. Bechtold, Ian R. Brown * \\ Department of Zoology, University of Toronto at Scarborough, 1265 Military Trail, West Hill, Toronto, Ontario, Canada M1C 1A4
}

Accepted 10 November 1999

\begin{abstract}
Stressful stimuli activate the heat shock (stress) response in which a set of heat shock proteins (hsps) is induced, which play roles in cellular repair and protective mechanisms. Most studies in the mammalian nervous system have focused on Hsp70, however, the present investigation targets other members of the induced set, namely Hsp27 and Hsp32. In response to hyperthermia, these hsps are strongly induced in Bergmann glial cells in the rat brain and transported into their radial fibers, which project into the 'synaptic-enriched' molecular layer of the cerebellum. Using subcellular fractionation and immunoelectron microscopy, hyperthermia-induced Hsp27 and Hsp32 were detected in synaptic elements and in perisynaptic glial processes. These results suggest that stress-induced Hsp27 and Hsp32 may contribute to repair and protective mechanisms at the synapse. (C) 2000 Elsevier Science B.V. All rights reserved.
\end{abstract}

Keywords: Hsp70; Hsp27; Stress response; Synapse; Hyperthermia; HO-1

\section{Introduction}

In response to a range of stressful stimuli, including hyperthermia and ischemia, the mammalian brain demonstrates a rapid and intense induction of the heat shock protein, Hsp70 [6,40,54]. The neuroprotective effects of Hsp70 have been demonstrated both in vitro and in vivo $[2,30,60,66,67]$ and it is well-established that a conditioning thermal stress increases neuronal survival during subsequent insults $[3,8,34,53]$. Recently, the protective effects of prior heat shock have been extended to neural specific phenomena such as synaptic function. For example, in collaborative studies, we have demonstrated that mild heat treatment of Drosophila larvae facilitates synaptic transmission at high test temperatures [20].

While Hsp70 is a major protein induced by cellular stress, it is not the only heat shock protein (hsp) which is up-regulated during activation of the heat shock (stress) response. A set of hsps is induced which includes the low molecular weight Hsp27 and also Hsp32, the stress-responsive form of heme oxygenase [12]. Studies have shown

\footnotetext{
* Corresponding author. Fax: +1-416-287-7642; e-mail: ibrown@scar.utoronto.ca
}

that overexpression of either Hsp27 or Hsp32 protects cells from subsequent stress $[26,27,31,41,46,59]$. In the present investigation, we have therefore examined the expression patterns of Hsp27 and Hsp32 in the rat brain in response to hyperthermia and also determined whether these hsps localize to synaptic sites following stress. These studies have focused on the cerebellum since its laminar structure facilitates the identification of cell types and zones enriched in synaptic termini are clearly defined.

\section{Materials and methods}

\subsection{Treatment of animals}

The body temperature of male Wistar rats (30-days-old) was raised $3.5^{\circ} \mathrm{C}$ above normal $\left(38^{\circ} \mathrm{C}\right)$ using a dry air incubator set to $42^{\circ} \mathrm{C}$. Body temperature of the animals was monitored with a rectal thermistor probe and maintained at the elevated temperature for $1 \mathrm{~h}$. Following incubation, the rats were placed at room temperature until time of sacrifice. At 30 days of age, the rats had achieved adult brain structure and synaptogenesis was essentially complete. 


\subsection{Immunocytochemistry}

Rats were anesthetized with sodium pentobarbital and perfused intracardially with $0.1 \mathrm{M}$ phosphate-buffered saline (PBS), $\mathrm{pH} 7.4$, followed by $4 \%$ paraformaldehyde in PBS. Brain tissue was removed and fixed overnight in $4 \%$ paraformaldehyde at $4^{\circ} \mathrm{C}$. Tissue was then equilibrated with 20\% sucrose in PBS, mounted in OCT embedding compound (Miles), and frozen at $-70^{\circ} \mathrm{C}$. Cryostat sections $(20 \mu \mathrm{m})$ were collected on gelatin-coated microscope slides and air-dried for $3 \mathrm{~h}$. Following rehydration in PBS-T buffer (0.1 M PBS, pH 7.4, 0.2\% Triton X-100, 0.1\% BSA), tissue sections were blocked in $5 \%$ goat serum in PBS-T for $1 \mathrm{~h}$. Sections were incubated overnight in primary antibody diluted to 1:25,000 for Hsp27 (StressGen, SPA-801), 1:7500 for Hsp32 (gift from P.R. Ortiz de Montellano, Department of Pharmaceutical Chemistry, University of California, San Francisco, CA), and 1:25,000 for Hsp70 [58] (gift from R. Tanguay, Laboratory of Cellular and Developmental Genetics, Université Laval, Ste-Foy, Quebec) in PBS-T. After washing, sections were incubated in biotinylated anti-rabbit IgG diluted in blocking buffer (1:400) for $90 \mathrm{~min}$. Brain sections were processed using the Vectastain Elite $\mathrm{ABC}$ kit (Vector Labs) and immunoreaction was visualized using 3,3'-diaminobenzidine (DAB). Sections were dehydrated in ethanol, cleared in xylene, and coverslipped for inspection and photography. Immunocytochemical results shown are representative of four separate animal trials. Omission of either the primary or secondary antibody resulted in clear sections with no disposition of reaction product.

\subsection{Isolation of subcellular fractions}

Animals were sacrificed by decapitation and brains were removed and separated into forebrain and cerebellum. Tissue was then rinsed with ice-cold saline to remove excess blood and subcellular fractions were prepared as follows: Tissue was subfractionated according to the method of Gurd et al. [15]. Briefly, brains (14-18 rats per preparation) were homogenized in $0.32 \mathrm{M}$ sucrose containing $1 \mathrm{mM} \mathrm{MgCl}$ and centrifuged twice for $5 \mathrm{~min}$ at 3200 $\mathrm{rpm}$. The supernatant (S1) was centrifuged at 13,000 rpm for 15 min resulting in $\mathrm{S} 2$ and $\mathrm{P} 2$. The $\mathrm{S} 2$ supernatant was spun at $12,000 \mathrm{rpm}$ for $10 \mathrm{~min}$. The resulting supernatant
(S2b) was centrifuged at 45,000 rpm for $1 \mathrm{~h}$ and provided microsomal (pellet) and cell soluble (supernatant) fractions. The $\mathrm{P} 2$ pellet was homogenized in $0.05 \mathrm{mM} \mathrm{CaCl}_{2}$. After $20 \mathrm{~min}$ at $4^{\circ} \mathrm{C}$, the homogenate was incubated with succinate and INT for $30 \mathrm{~min}$ at $37^{\circ} \mathrm{C}$. Membrane fractions were separated on a discontinuous sucrose gradient by centrifugation at 26,000 rpm for $90 \mathrm{~min}$ and harvested as follows: light membranes (LM) at the $0.8 / 1.0 \mathrm{M}$ sucrose interface and synaptic membranes (SMs) from the 1.0/1.2 M sucrose interface. Synaptic junctions (SJs) were isolated by the extraction of the SM fraction with Triton X-100 $(0.5 \% \mathrm{v} / \mathrm{v})$. Mitochondria were collected from the pellet of the sucrose gradient spin and washed in ice-cold acetone to remove INT.

\subsection{Gel electrophoresis and Western blot analysis}

Protein samples were separated by electrophoresis on $15 \%$ SDS polyacrylamide gels with a 5\% stacking gel using a Tris/Tricine buffer system. Following protein transfer, nitrocellulose blots were stained with Ponceau $\mathrm{S}$ to ensure equal protein loading. Blots were blocked for $5 \mathrm{~h}$ in 5\% Carnation milk powder in TBST (10 mM Tris, 0.25 $\mathrm{M} \mathrm{NaCl}, 0.05 \%$ Tween, $\mathrm{pH} 7.5$ ), then incubated 14-16 h with either Hsp27 or Hsp32 antibody diluted 1:10,000 in $1 \%$ purified BSA in TBST containing $0.02 \%$ sodium azide. After washing, blots were incubated for $2 \mathrm{~h}$ with anti-rabbit IgG (Sigma) diluted $1: 10,000$ in $1 \%$ BSA in TBST. Immunoreactivity was visualized using ECL detection reagents (Amersham, RPN 2106). Subcellular fractions were collected from a minimum of three separate trials and Western blots shown are representative of repeat experiments on each set of fractions.

\subsection{Immunoelectron microscopy}

Rats were perfused as above using 3.5\% glutaraldehyde in PBS. Brain tissue was removed, cut into $3 \mathrm{~mm}$ slabs and fixed for an additional $2 \mathrm{~h}$ at $4^{\circ} \mathrm{C}$. Tissue was then immersed in $0.1 \%$ sodium borohydride in PBS for $30 \mathrm{~min}$. After extensive washes, $40 \mu \mathrm{m}$ sections were cut using a vibratome. Cerebellar sections were equilibrated to $30 \%$ sucrose and quick-frozen in isopentane cooled to $-70^{\circ} \mathrm{C}$ to increase antibody penetration. Non-specific immunoreaction was blocked by incubating the tissue sections for 90

\footnotetext{
Fig. 1. Time course analysis of Hsp27 expression in the rat cerebellum following hyperthermia. Hsp27 was not detected in the cerebellum in the absence of stress (Panel A); however, immunoreactive staining of microvasculature was observed $5 \mathrm{~h}$ after hyperthermia (Panel B). The inset in Panel B shows a higher magnification of the induced Hsp27 signal in the microvasculature. By $15 \mathrm{~h}$ (Panel C), pronounced Hsp27-immunoreactivity was evident in the Purkinje cellular layer (p). Hsp27 was localized to the parallel arrays of Bergmann glial fibers lying within the molecular layer (m) $24 \mathrm{~h}$ after hyperthermia (Panel D, arrowheads). dwm, deep white matter; g, granule cell layer; m, molecular layer; p, Purkinje cellular layer. Bar $=250 \mu \mathrm{m}$.
} 

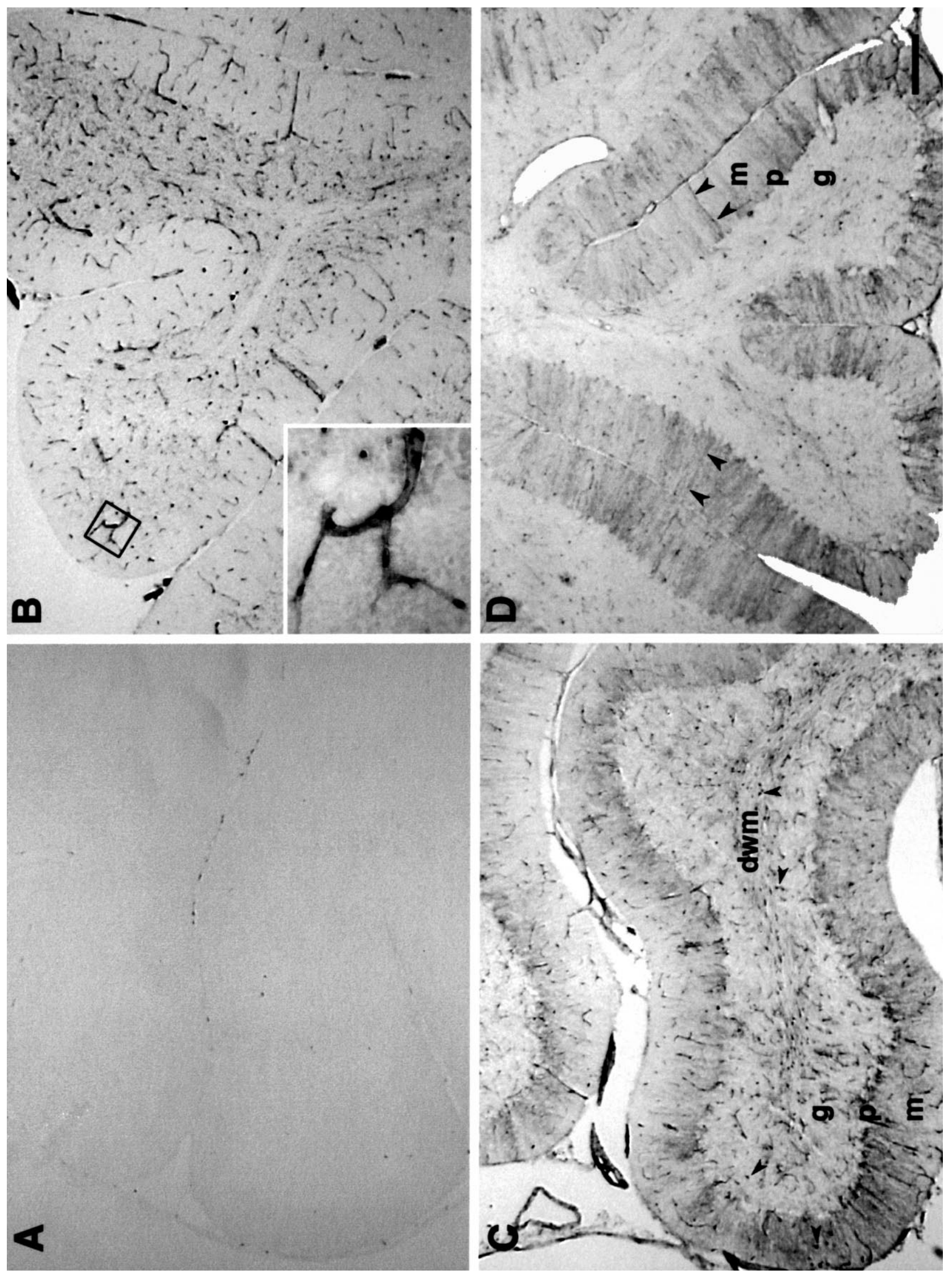
min with $10 \%$ goat serum in PBS. Primary antibodies were diluted in blocking buffer at 1:7500 for Hsp70, 1:7500 for Hsp25, and 1:3000 for Hsp32 and incubated with the tissue sections for $24-36 \mathrm{~h}$ at $4^{\circ} \mathrm{C}$. Sections were washed and immersed in biotinylated anti-rabbit $\operatorname{IgG}$ diluted 1:800 in blocking buffer for $2.5 \mathrm{~h}$. Sections were processed using the Vectastain Elite ABC kit (Vector Labs) and visualized with DAB. After fixation in $1 \% \mathrm{OsO}_{4}$ in $\mathrm{PBS}$ for $30 \mathrm{~min}$ sections were dehydrated and embedded in Epon 812 resin (EM Sciences). Ultrathin sections were collected on uncoated copper grids and counterstained with uranyl acetate and lead citrate. Counterstaining was omitted on certain sections to verify localization of DAB reaction product. Grids were examined and photographed using a Siemens Elmiskop102. No reaction product was detected after omission of either the primary or secondary antibody. Electron micrographs are representative of a minimum of three animal trials for control and hyperthermic conditions.

\section{Results}

\subsection{Expression of hsps in the rat cerebellum in response to hyperthermia}

Immunocytochemistry was employed to examine the pattern of Hsp27 and Hsp32 expression in the rat cerebellum following hyperthermia. Constitutive expression of these hsps was not detected in control animals (Fig. 1A and Fig. 2A); however, a robust induction was apparent following thermal stress. At $5 \mathrm{~h}$ post-hyperthermia, Hsp27 induction was observed in the microvasculature system of the cerebellum (Fig. 1B) and by $15 \mathrm{~h}$, a prominent signal was apparent in the Purkinje cellular layer (labeled ' $p$ ' in Fig. 1C). Analysis at higher magnification (Fig. 4A) revealed that Hsp27 induction in this cerebellar layer was localized to Bergmann glial cell bodies (bg) while adjacent Purkinje neurons (asterisks) were immuno-negative. In addition, Hsp27 was also detected in the proximal zone of the glia fibers (arrowheads), which radiate from the Bergmann glial cell bodies into the molecular layer. As seen in Fig. 1C, Hsp27 was also expressed by glial cells (arrowheads) in the molecular layer $(\mathrm{m})$, granule cell layer (g) and the deep white matter (dwm) $15 \mathrm{~h}$ after hyperthermia. By $24 \mathrm{~h}$ (Fig. 1D), the Hsp27 signal spanned the entire width of the molecular layer due to staining of both the proximal and distal segments of the Bergmann glial radial fibers.
In response to hyperthermia, Hsp32, the stress-responsive form of heme oxygenase, showed a similar pattern of induction compared to Hsp27 in Bergmann glial cells and their radial fibers (Figs. 2 and 4B). However, Hsp32 induction in these cells was earlier in onset (i.e., prominent at $5 \mathrm{~h}$ post-hyperthermia) and was not observed in the microvascular system (Fig. 2B). In addition to the Purkinje cellular layer (p), Hsp32 was also expressed in glial cells (arrowheads) in the molecular $(\mathrm{m})$ and granule cell $(\mathrm{g})$ layers as well as the deep white matter (dwm) (Fig. 2B).

For comparative purposes, Hsp70 induction was also examined and a strikingly different pattern of expression was apparent relative to that noted for Hsp27 and Hsp32. An intense induction of Hsp70 was detected in the granule cell layer $(\mathrm{g})$ of the cerebellum at 5,15 , and $24 \mathrm{~h}$ post-hyperthermia (Fig. 3). At higher magnification (Fig. 4), it was apparent that granule neurons (gn) showed a robust induction of Hsp70 while Bergmann glial cell bodies and their radial fibers were immuno-negative. In addition, scattered glial cells (arrowheads) in the molecular layer (m) and deep white matter (dwm) showed an induction of Hsp70 (Fig. 3B).

In summary, these results revealed pronounced differences in the pattern of expression of these hsps in the rat cerebellum following hyperthermia. Hsp70 induction was most pronounced in granule neurons. Hsp27 and Hsp32 were induced in Bergmann glial cell bodies, with a robust transport of these hsps into the radial glial fibers of these cells which project into the 'synapse-rich' molecular layer of the cerebellum. It is noteworthy that Hsp27 was induced in the cerebellar microvasculature at $5 \mathrm{~h}$ post-hyperthermia, however, Hsp32 and Hsp70 were not. The significance of this finding is not known.

\subsection{Subcellular distribution of Hsp27 and Hsp32}

Western blots of total cerebellar homogenates (CB) confirmed the immunocytochemical observations that Hsp27 and Hsp32 were not detected in control animals and that a prominent induction was apparent after hyperthermia (Fig. 5A and B, respectively). A similar pattern of induction was observed in the forebrain (FB) (Fig. 5A and B). Subcellular fractionation revealed that Hsp27 was enriched in the cell soluble fraction, while Hsp32 was prominent in the microsome fraction, as expected since heme oxygenase is known to integrate into microsomal membranes [68].

Fig. 2. Induction of Hsp32 protein in the cerebellum following hyperthermia. Immunocytochemistry using an Hsp32-specific antibody showed no reactivity in the control cerebellum (Panel A). Intense Hsp32 staining of the Purkinje cellular layer (p) was observed 5 and 15 h following hyperthermia (Panels B and C). By $24 \mathrm{~h}$ after hyperthermia, Hsp32 was evident throughout Bergmann glial fibers (arrowheads), which span the width of the molecular layer (m) of the cerebellum (Panel D). dwm, deep white matter; g, granule layer; m, molecular layer; p, Purkinje layer. Bar $=250 \mu \mathrm{m}$. 

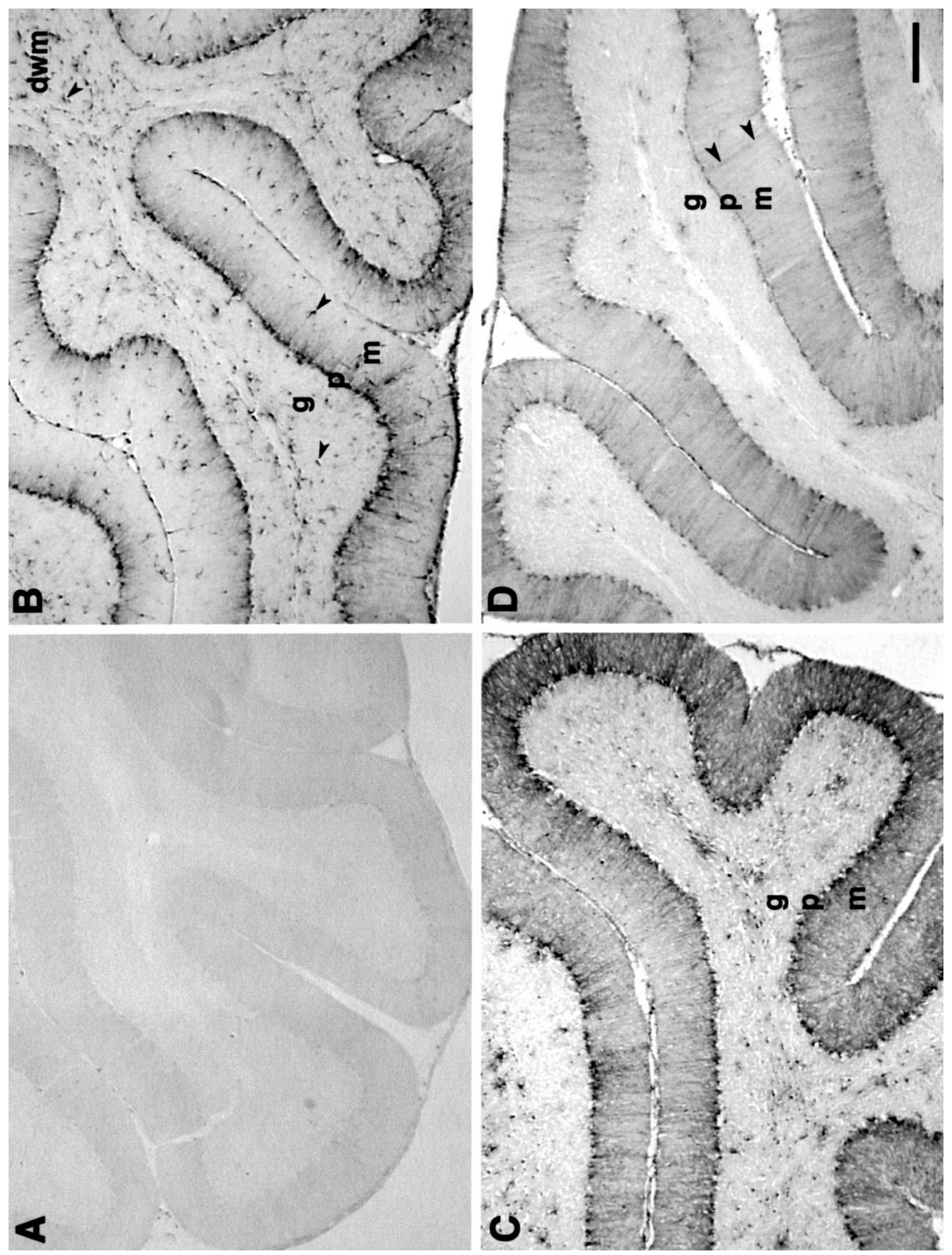

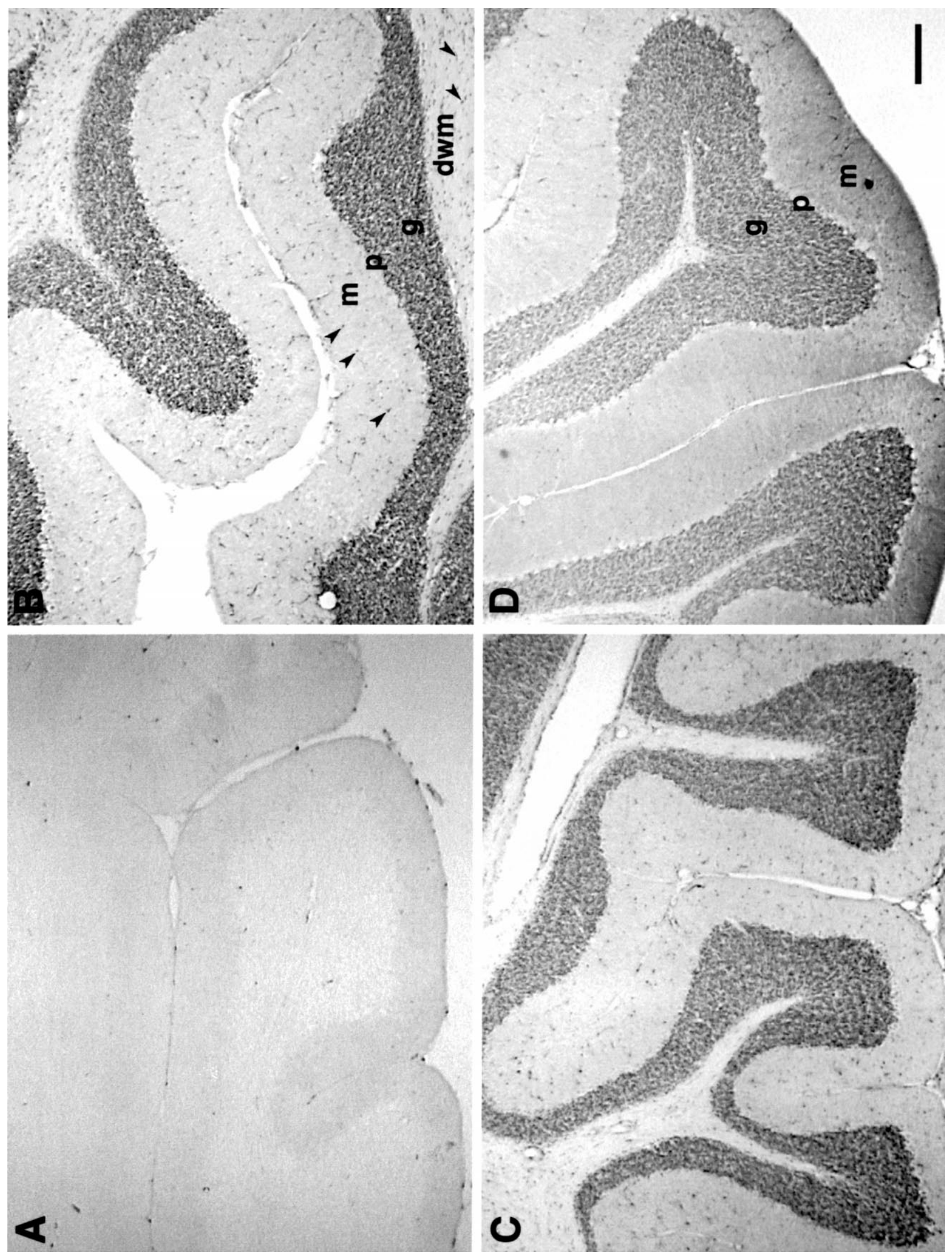
Synaptic membrane (SM) and synaptic junctions (SJ) were isolated and subject to Western blot analysis. These fractions, which have been fully characterized by biochemical and electron microscope studies [9,14], include both presynaptic and postsynaptic elements. As indicated in Fig. 6, both Hsp27 and Hsp32 were detected in SMs and SJs isolated from the cerebellum and forebrain following hyperthermia. Extraction of the SM fraction with Triton $\mathrm{X}-100$ removes much of the plasma membranes that surround the synaptic cleft and yields a purified SJ fraction [15]. At 5 h post-hyperthermia, Hsp27 and Hsp32 signals were stronger in the SJs than the SMs.

\subsection{Visualization of stress-induced Hsp27 and Hsp32 at synaptic sites following hyperthermia}

To further localize the cellular sites of deposition of the stress-induced Hsp27 and Hsp32, immunoelectron microscopy was carried out. Both induced hsps localized to postsynaptic sites in the molecular layer of the cerebellum $15 \mathrm{~h}$ following hyperthermia (indicated as 'Po' in Fig. 7B and $\mathrm{E})$. In agreement with light microscopy observations shown in Figs. 1 and 2, Hsp27 and Hsp32 signals were not detected in the unstressed animals (Fig. 7A and D). Stress-induced Hsp27- and Hsp32-immunoreactivity were also localized to perisynaptic glial processes $(\mathrm{g})$, which ensheath synapses in the molecular layer (Fig. 7C and F, respectively).

\section{Discussion}

It is well-established that the induction of hsps following stress contributes to cellular repair and protective mechanisms $[25,47]$ and that a prior heat shock protects the nervous system from subsequent stress $[6,40,54]$. Our recent collaborative work has shown that heat shock protects synaptic transmission from subsequent stressful conditions [20]. Most studies in the nervous system have focused on Hsp70, however, the present work investigates other members of the set of stress-inducible hsps. In this report, we examine the expression patterns of Hsp27 and Hsp32 in the rat brain following whole body hyperthermia. Using subcellular fractionation and immunoelectron microscopy, our results demonstrate the localization of hyperthermia-induced Hsp27 and Hsp32 to synaptic sites in the rat brain, suggesting that these hsps may participate in the repair and protection of synaptic components.

Interestingly, our observations implicate glial cells as the primary source of the stress-induced Hsp27 and Hsp32, which associate with synaptic elements. Glial cells are involved in many aspects of neuronal physiology [24], therefore, it seems likely that the induction of hsps by glia during stress benefits neurons. In cell culture studies, glia have been shown to protect neurons from severe stress $[5,42,63]$. In vivo, the loss of glial function, mediated by fluorocitrate poisoning, increases neuronal vulnerability to spreading depression and leads to massive neuron damage [29].

Our present results indicate that Bergmann glial cells, which are specialized radial astrocytes that interact closely with the cerebellar Purkinje neurons, exhibit a pronounced induction of Hsp27 and Hsp32 following hyperthermia. Time course immunocytochemistry observations demonstrated the subsequent movement of Hsp27 and Hsp32 into the 'synapse-rich' molecular layer of the cerebellum via radial fibers which extend from these cells. The intimate association of these glial fibers with thousands of synapses $[13,51]$ suggests that stress-induced Hsp27 and Hsp32 are in close proximity to synaptic structures. This was confirmed by immunoelectron microscopy observations, which demonstrated the localization of Hsp27 and Hsp32 to perisynaptic glial processes following hyperthermia. Perisynaptic glia are involved in many aspects of synaptic function including the uptake, synthesis, and release of excitatory amino acids, such as glutamate [4,24,52]. Damage to glial components which regulate neurotransmitter levels in the synaptic cleft during stress could lead to major changes in synaptic activity. During ischemia, the failure of glial uptake of extracellular glutamate contributes to excitotoxic neuronal injury [7]. In rat models, severe hyperthermia induces seizure and in some cases, status epilepticus [19,44]. Localization of Hsp27 and Hsp32 to perisynaptic glial processes following hyperthermia could facilitate repair of stress-induced synaptic damage. The maintenance of perisynaptic glial function by Hsp27 and $\mathrm{Hsp} 32$ during stress could play a role in the protection of synaptic transmission by prior heat shock. It is of interest that other studies have noted an induction of Hsp27 or Hsp32 in glial elements following a range of stresses, such as ischemia $[21,22,45]$, cortical application of potassium chloride [49], photothrombotic injury [48], experimental subarachnoid hemorrhage [38,39], and kainic acid-induced seizures $[23,50]$.

Fig. 3. Time course analysis of Hsp70 expression in the rat cerebellum following hyperthermia. Immunocytochemical analysis of Hsp70 in the rat cerebellum following hyperthermia demonstrated a strong induction at 5, 15, and $24 \mathrm{~h}$ (Panels B-D) within the granule cell layer (g) and scattered glial cell populations (arrowheads) in the molecular layer $(\mathrm{m})$ and deep white matter (dwm). Hsp70 was not detectable in the unstressed cerebellum (Panel A). $\mathrm{dwm}$, deep white matter; g, granule cell layer; $\mathrm{m}$, molecular layer; $\mathrm{p}$, Purkinje layer. Bar $=250 \mu \mathrm{m}$. 

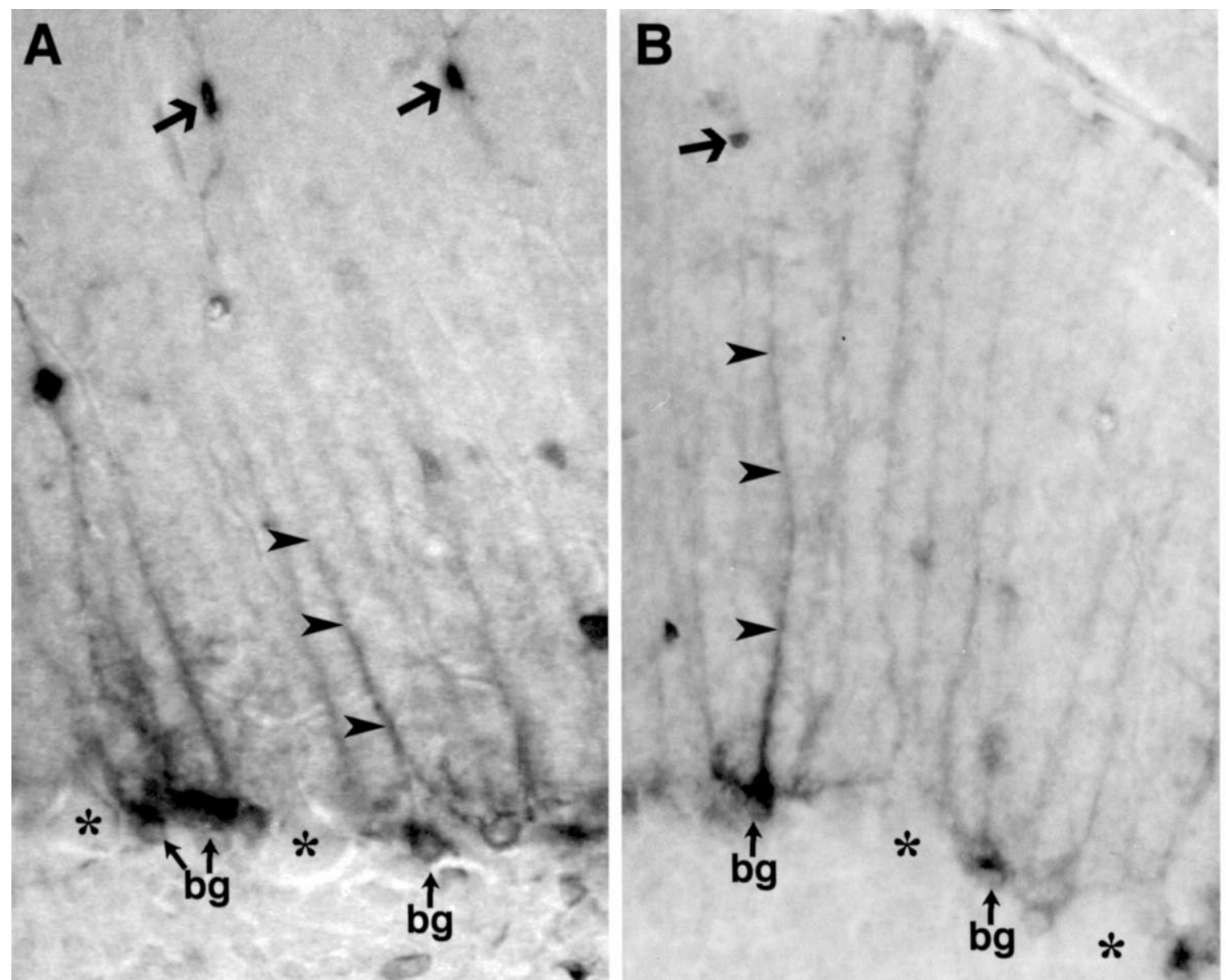

\section{C}

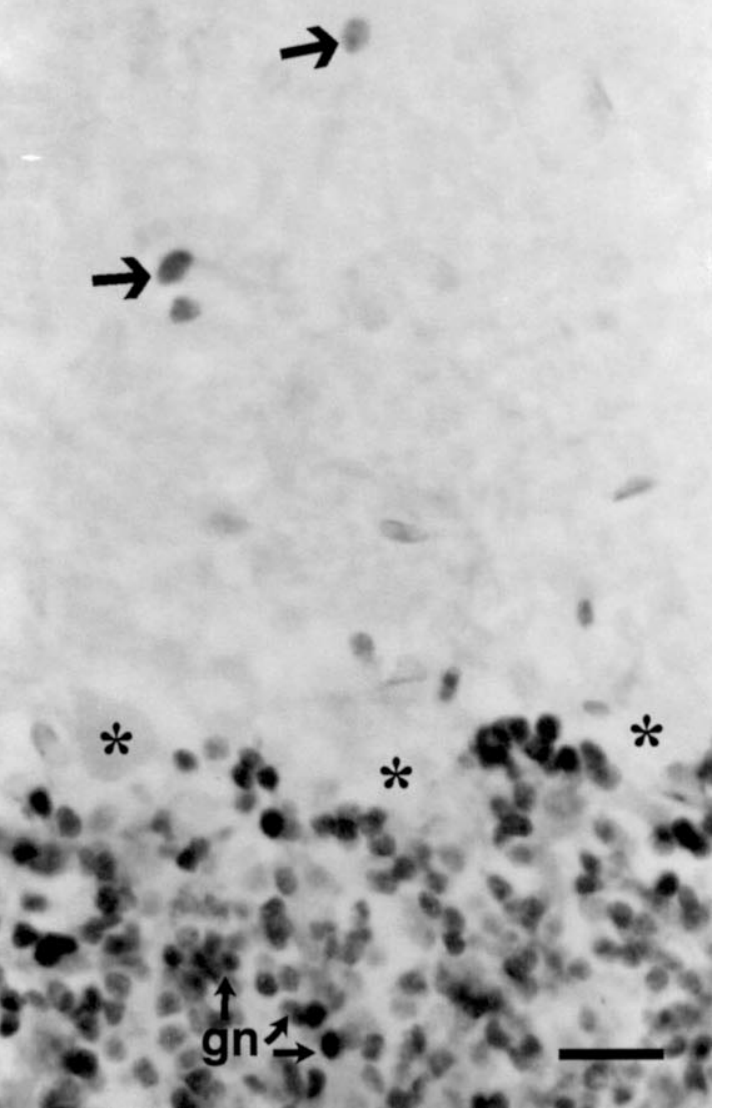

Fig. 4. Localization of Hsp27, Hsp32, and Hsp70 in layers of the cerebellum. Analysis of Hsp27, Hsp32, and Hsp70 immunocytochemistry was carried out at high magnification on the 15 h post-hyperthermic rat cerebellar cortex. Hsp27- and Hsp32-immunoreactivity were detected in the Bergmann glial cell bodies (bg) and radial fibers (arrowheads) which extend from these cells (Panels A and B, respectively). Hsp70 was not detected in these glial cells (Panel C) but was prominent in granule neurons (gn). All three hsps were observed in scattered glial cells in the molecular layer (arrows). Purkinje neurons exhibited no immunoreactivity to Hsp27, Hsp32, or Hsp70 (asterisks). bg, Bergmann glia; gn, granule neuron; *, Purkinje neurons. Bar $=20 \mu \mathrm{m}$. 


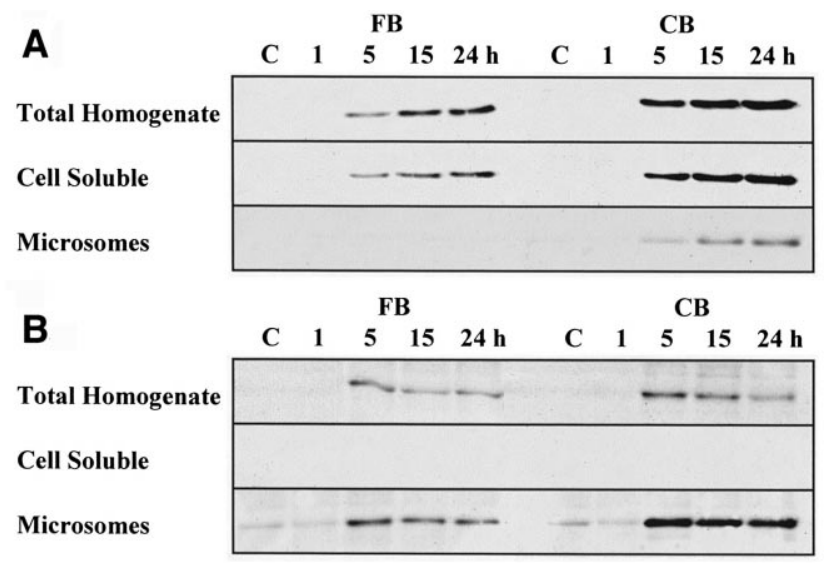

Fig. 5. Distribution of stress-induced Hsp27 and Hsp32 in subcellular fractions of the post-hyperthermic rat brain. Induction of Hsp27 (Panel A) and Hsp32 (Panel B) in the rat brain following hyperthermia was evident in total tissue homogenate fractions of the forebrain $(\mathrm{FB})$ and cerebellum (CB). The accumulation of stress-induced Hsp27 was greatest in the cell soluble fraction, while Hsp32 was enriched in the microsome fraction. h, hours

Analysis of subcellular fractions demonstrated the accumulation of Hsp27 and Hsp32 in SM and SJ fractions following hyperthermia. The association of these hsps with the synapse after stress was confirmed by EM immunocytochemistry. Hsp27- and Hsp32-immunoreactivity were localized to postsynaptic terminals of the rat cerebellum 15 $\mathrm{h}$ following hyperthermic stress. Since few studies have explored how the heat shock response impacts on synaptic transmission, potential actions of Hsp27 and Hsp32 at the synapse during stress have not been considered.

Hsp27 is known to regulate actin polymerization $[28,43]$ and elevated levels of Hsp27 stabilize microfilaments during stress $[31,32]$. Furthermore, Hsp27 prevents protein aggregation during heat shock and facilitates the correct refolding of damaged proteins under permissive conditions $[11,17,18]$. Once localized to the synapse, Hsp27 could repair stress-induced damage to the synaptic proteins, including cytoskeletal components and could protect the synapse from subsequent insults. Actin is a major structural component of the postsynaptic density [1]. The localization of Hsp27 to postsynaptic terminals, which is noted in the present study, may contribute to the stabilization of PSD structures during stress.

The contribution of Hsp32 to the recovery of normal cellular activity following stress is likely to include the breakdown of damaged hemoproteins. Hsp32 metabolizes heme to $\mathrm{Fe}$, carbon monoxide (CO), and biliverdin [35]. Elevated levels of $\mathrm{CO}$ and biliverdin, which is rapidly converted to bilirubin, may modulate synaptic activity during stress. Bilirubin, a potent antioxidant has been shown to provide protection against oxidative damage $[10,33]$. CO has been characterized as a neural messenger, which regulates cGMP levels through the activation of guanylyl cyclase $[36,62]$ and has been implicated in the regulation of synaptic glutamate release [56]. $\mathrm{CO}$ has similar physiological properties to nitric oxide (NO), another putative neuromessenger [57]. Maines et al. [37], demonstrated that NO production in the brain is reduced by $50 \%$ following heat shock and suggested that CO, produced by $\mathrm{Hsp} 32$ induced metabolism of heme, may compensate for this loss. Nitric oxide synthase (NOS) is an intrinsic component of the PSD and NO stimulates $\mathrm{Ca}^{2+} /$ calmodulin-dependent kinase phosphorylation of PSD proteins [65]. The possibility that CO plays a similar role during stress is supported by our observation of the localization of Hsp32 (HO-1) to postsynaptic structures following hyperthermia.

In the present study, hyperthermia-induced expression of Hsp27 or Hsp32 was observed in Bergmann glial cells and their radial fibers which project into the 'synaptic-enriched' molecular layer of the cerebellum. The additional detection of Hsp27 and Hsp32 in synaptic structures by immunoelectron microscopy and subcellular fractionation raises the possibility of a stress-induced transfer of hsps from perisynaptic glial processes to the nerve terminal. Previous studies have demonstrated a heat-induced glial to axon transfer of hsps in the invertebrate nervous system [55,61]. A similar mechanism has been suggested in the mammalian nervous system [22,64]. In addition, cultured rat embryo cells can be stimulated to selectively secrete hsps [16]. Intraocular injection of purified Hsp70 shields photoreceptors from subsequent bright light induced degeneration [60], suggesting that these neurons are capable of taking up and benefiting from exogenous hsps. A glial to nerve terminal transfer of hsps would allow the nervous system to rapidly induce hsps following stressful stimuli and transport them to synaptic sites which are distant from the neuronal cell body.

In summary, the present report demonstrates the localization of stress-induced Hsp27 and Hsp32 to synaptic

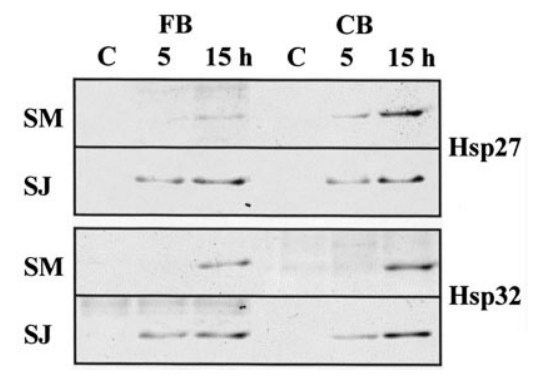

Fig. 6. Association of $\mathrm{Hsp} 27$ and $\mathrm{Hsp} 32$ with synaptic fractions after hyperthermia. Analysis of SM and SJ fractions isolated from the forebrain (FB) and cerebellum (CB) of post-hyperthermic rats demonstrated increases in both Hsp27 and Hsp32. Both proteins accumulated in the SM fractions $15 \mathrm{~h}$ after hyperthermia. Hsp27 and Hsp32 were evident in the SJ fractions of 5 and $15 \mathrm{~h}$ post-hyperthermic animals. h, hours. 

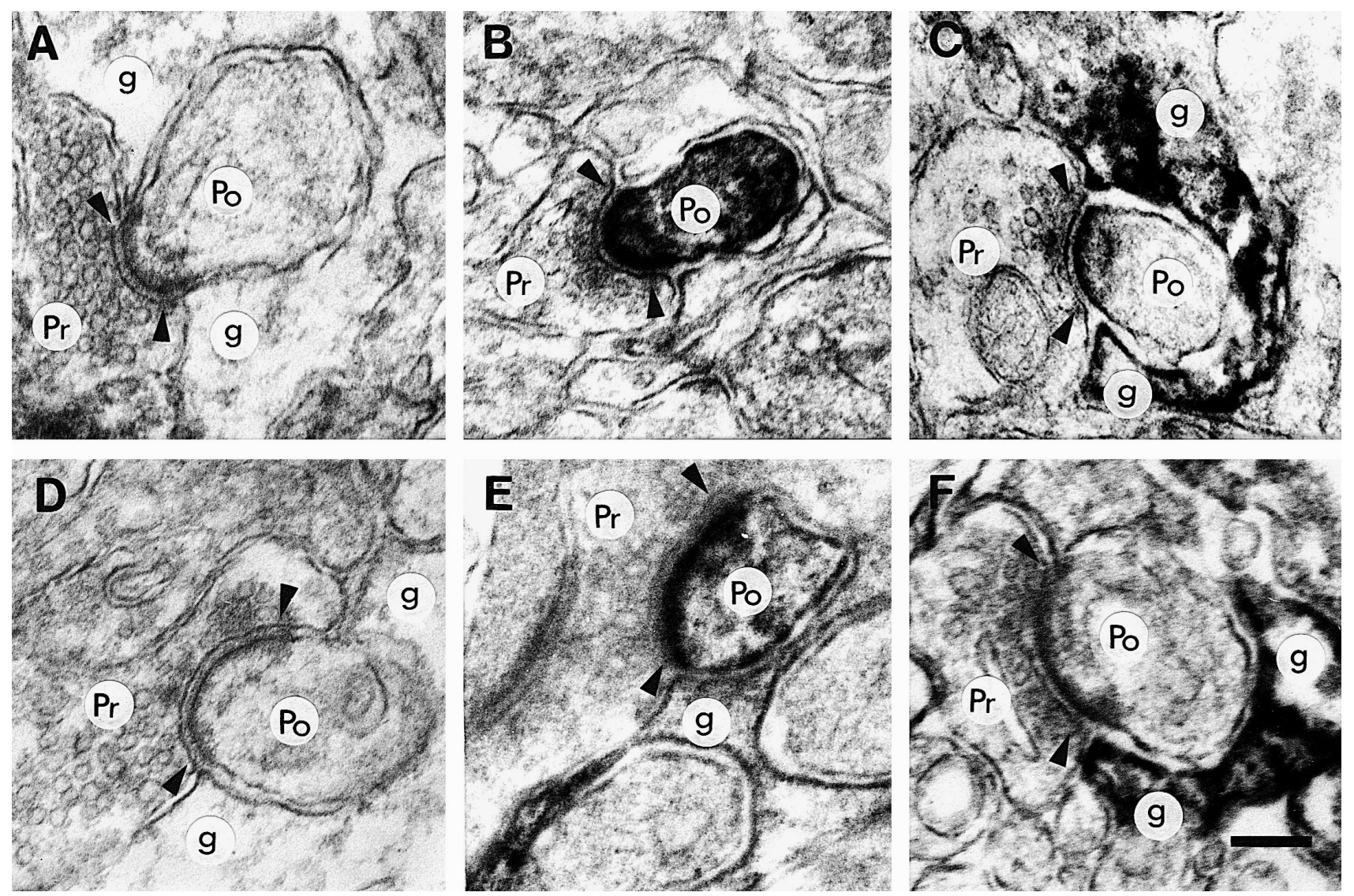

Fig. 7. Visualization of Hsp27 and Hsp32 at synaptic sites in the cerebellum following hyperthermia. Electron microscopic immunocytochemistry was performed on cerebellar tissue isolated from $15 \mathrm{~h}$ post-hyperthermic animals (A-C: Hsp27 immunocytochemistry; D-F: Hsp32 immunocytochemistry). Stress-induced Hsp27 and Hsp32 localized to postsynaptic structures (Po) in the molecular layer of the cerebellum (Panels B and E). Immunoreactive product was not detected in synapses of control animals (Panels A and D). Hsp27- and Hsp32-immunoreactivity were also observed in perisynaptic glial processes ('g' in Panels C and F). Arrowheads mark synaptic connections. g, glial processes; Po, postsynaptic terminal; Pr, presynaptic terminal. Bar = 200 $\eta \mathrm{m}$.

sites following hyperthermia where these hsps may contribute to synaptic repair and protective mechanisms.

\section{Acknowledgements}

We thank Sheila Rush, Nankie Bissoon and Prof. James Gurd for technical advice on subcellular fractionation. We also thank Raymond Or for his electron microscope expertise and R. Tanguay and P.R. Ortiz de Montellano for donation of antibodies (971 from R.T., HO-1 from P.R.O.M.). This research was supported by grants to I.R.B. from the Medical Research Council of Canada.

\section{References}

[1] G. Adam, A. Matus, Role of actin in the organization of brain postsynaptic densities, Mol. Brain Res. 43 (1996) 246-250.

[2] V. Amin, D.V. Cumming, R.S. Coffin, D.S. Latchman, The degree of protection provided to neuronal cells by a pre-conditioning stress correlates with the amount of heat shock protein 70 it induces and not with the similarity of the subsequent stress, Neurosci. Lett. 200 (1995) 85-88.

[3] M.F. Barbe, M. Tytell, D.J. Gower, W.J. Welch, Hyperthermia protects against light damage in the rat retina, Science 241 (1988) $1817-1820$

[4] B.A. Barres, New roles for glia, J. Neurosci. 11 (1991) 3685-3694.

[5] D.R. Brown, Neurons depend on astrocytes in a coculture system for protection from glutamate toxicity, Mol. Cell Neurosci. 13 (1999) 379-389.

[6] I.R. Brown, F.R. Sharp, The cellular stress gene response in brain, in: D.S. Latchman (Ed.), Stress Proteins, Handbook of Experimental Pharmacology. Springer, Heidelburg, 1999, pp. 243-263.

[7] D.W. Choi, S.M. Rothman, The role of glutamate neurotoxicity in hypoxic-ischemic neuronal death, Annu. Rev. Neurosci. 13 (1990) $171-182$

[8] M. Chopp, H. Chen, K.-L. Ho, M.O. Dereski, E. Brown, F.W. Hetzel, K.M. Welch, Transient hyperthermia protects against subsequent forebrain ischemic cell damage in the rat, Neurology 39 (1989) 1396-1398.

[9] R.A. Clark, J.W. Gurd, N. Bissoon, N. Tricaud, E. Molnar, S.E. Zamze, R.A. Dwek, R.A. McIlhinney, D.R. Wing, Identification of lectin-purified neural glycoproteins, GPs 180, 116, and 110, with NMDA and AMPA receptor subunits: conservation of glycosylation at the synapse, J. Neurochem. 70 (1998) 2594-2605. 
[10] S. Dore, M. Takahashi, C.D. Ferris, L.D. Hester, D. Guastella, S.H. Snyder, Bilirubin, formed by activation of heme oxygenase-2, protects neurons against oxidative stress injury, Proc. Natl. Acad. Sci. U. S. A. 96 (1999) 2445-2450.

[11] M. Ehrnsperger, S. Graber, M. Gaestel, J. Buchner, Binding of non-native protein to Hsp25 during heat shock creates a reservoir of folding intermediates for reactivation, EMBO J. 16 (1997) 221-229.

[12] J.F. Ewing, M.D. Maines, Rapid induction of heme oxygenase 1 mRNA and protein by hyperthermia in rat brain: heme oxygenase 2 is not a heat shock protein, Proc. Natl. Acad. Sci. U. S. A. 88 (1991) 5364-5368.

[13] J. Grosche, V. Matyash, T. Moller, A. Verkhratsky, A. Reichenbach, H. Kettenmann, Microdomains for neuron-glia interaction: parallel fiber signaling to Bergmann glial cells, Nat. Neurosci. 2 (1999) 139-143.

[14] J.W. Gurd, Protein tyrosine phosphorylation: implications for synaptic function, Neurochem. Int. 31 (1997) 635-649.

[15] J.W. Gurd, N. Bissoon, J. Soulliere, Procedures for analyzing the tyrosine phosphorylation of synaptic glycoproteins, NeuroProtocols 1 (1992) 207-214.

[16] L.E. Hightower, P.T. Guidon Jr., Selective release from cultured mammalian cells of heat-shock (stress) proteins that resemble gliaaxon transfer proteins, J. Cell. Physiol. 138 (1989) 257-266.

[17] U. Jakob, M. Gaestel, K. Engel, J. Buchner, Small proteins are molecular chaperones, J. Biol. Chem. 268 (1993) 1517-1520.

[18] U. Jakob, H. Lilie, I. Meyer, J. Buchner, Transient interaction of Hsp90 with early intermediates of citrate synthase, implications for heat shock in vivo, J. Biol. Chem. 270 (1995) 7288-7294.

[19] W. Jiang, T.M. Duong, N.C. de Lanerolle, The neuropathology of hyperthermic seizures in the rat, Epilepsia 40 (1999) 5-19.

[20] S. Karunanithi, J.W. Barclay, R.M. Robertson, I.R. Brown, H.L. Atwood, Neuroprotection at Drosophila synapses conferred by prior heat shock, J. Neurosci. 19 (1999) 4360-4369.

[21] H. Kato, Y. Liu, K. Kogure, K. Kato, Induction of 27-kDa heat shock protein following cerebral ischemia in a rat model of ischemic tolerance, Brain Res. 634 (1994) 235-244.

[22] H. Kato, K. Kogure, X.H. Liu, T. Araki, K. Kato, Y. Itoyama, Immunohistochemical localization of the low molecular weight stress protein Hsp27 following focal ischemia in the rat, Brain Res. 679 (1995) 1-7.

[23] K. Kato, R. Katoh-Semba, I.K. Takeuchi, H. Ito, K. Kamei, Responses of heat shock proteins hsp27, alpha $\beta$-crystallin, and hsp70 in rat brain after kainic acid-induced seizure activity, J. Neurochem. 73 (1999) 229-236.

[24] H. Kettenmann, B.R. Ransom (Eds.) Neuroglia. Oxford Univ. Press, New York, 1995, 1104 pp.

[25] J.G. Kiang, G.C. Tsokos, Heat shock protein $70 \mathrm{kDa}$ : molecular biology, biochemistry, and physiology, Pharmacol. Ther. 80 (1998) 183-201.

[26] J. Landry, P. Chretien, H. Lambert, E. Hickey, L.A. Weber, Heat shock resistance conferred by expression of the human Hsp27 gene in rodent cells, J. Cell Biol. 109 (1989) 7-15.

[27] J. Landry, P. Chretien, A. Laszlo, H. Lambert, Phosphorylation of Hsp27 during development and decay of thermotolerance in Chinese hamster cells, J. Cell Physiol. 147 (1991) 93-101.

[28] J. Landry, J. Huot, Modulation of actin dynamics during stress and physiological stimulation by a signaling pathway involving p38 MAP kinase and heat-shock protein 27, Biochem. Cell Biol. 73 (1995) 703-707.

[29] C. Largo, P. Cuevas, G.G. Somjen, R. Martin del Rio, O. Herreras, The effect of depressing glial function in rat brain in situ on ion homeostasis, synaptic transmission, and neuron survival, J. Neurosci. 16 (1996) 1219-1229.

[30] D.S. Latchman, Cell stress genes and neuronal protection, Neuropathol. Appl. Neurobiol. 21 (1995) 475-477.

[31] J.N. Lavoie, G. Gingras-Breton, R.M. Tanguay, J. Landry, Induction of Chinese hamster HSP27 gene expression in mouse cells confers resistance to heat shock. Hsp27 stabilization of the microfilament organization, J. Biol. Chem. 286 (1993) 3420-3429.

[32] J.N. Lavoie, H. Lambert, E. Hickey, L.A. Weber, J. Landry, Modulation of cellular thermoresistance and actin filament stability accompanies phosphorylation-induced changes in the oligomeric structure of heat shock protein 27, Mol. Cell Biol. 15 (1995) 505-516.

[33] S.F. Llesuy, M.L. Tomaro, Heme oxygenase and oxidative stress, Evidence of involvement of bilirubin as physiological protector against oxidative damage, Biochim. Biophys. Acta 1223 (1994) 9-14.

[34] D.H. Lowenstein, P.H. Chan, M.F. Miles, The stress protein response in cultured neurons: characterization and evidence for a protective role in excitotoxicity, Neuron 7 (1991) 1053-1060.

[35] M.D. Maines, Heme oxygenase: function, multiplicity, regulatory mechanisms, and clinical applications, FASEB J. 2 (1988) 25572568.

[36] M.D. Maines, The heme oxygenase system: a regulator of secondary messenger gases, Annu. Rev. Pharmacol. Toxicol. 37 (1997) 517554.

[37] M.D. Maines, B.C. Eke, C.M. Weber, J.F. Ewing, Corticosterone has a permissive effect on expression of heme oxygenase- 1 in CA1-CA3 neurons of hippocampus in thermal-stressed rats, J. Neurochem. 64 (1995) 1769-1779.

[38] P. Matz, C. Turner, P.R. Weinstein, S.M. Massa, S.S. Panter, F.R. Sharp, Heme oxygenase-1 induction in glia throughout rat brain following experimental subarachnoid hemorrhage, Brain Res. 713 (1996) 211-222.

[39] P. Matz, P.R. Weinstein, F.R. Sharp, Heme oxygenase-1 and heat shock protein 70 induction in glia and neurons throughout rat brain after experimental intracerebral hemorrhage, Neurosurgery 40 (1997) $152-160$.

[40] R.J. Mayer, I.R. Brown (Eds.), Heat Shock Proteins in the Nervous System. Academic Press, London, 1994, 297 pp.

[41] P. Mehlen, X. Préville, P. Chareyon, J. Briolay, R. Klementz, A.P. Arriago, Constitutive expression of human Hsp27, Drosophila Hsp27, or alpha B-crystallin confer resistance to TNF- and oxidative stressinduced cytotoxicity in stably transfected murine L929 fibroblasts, J. Immunol. 154 (1995) 363-374.

[42] M.A. Mena, M.J. Casarejos, A. Carazo, C.L. Paino, J. Garcia de Yebenes, Glia protect fetal midbrain dopamine neurons in culture from L-DOPA toxicity through multiple mechanisms, J. Neural. Transm. 104 (1997) 317-328.

[43] T. Miron, K. Vancompernolle, J. Vandekerckhove, M. Wilchek, B. Geiger, A $25-\mathrm{kD}$ inhibitor of actin polymerization is a low molecular mass heat shock protein, J. Cell Biol. 114 (1991) 255-261.

[44] T. Morimoto, H. Nagao, N. Sano, M. Takahashi, H. Matsuda, Electroencephalographic study of rat hyperthermic seizures, Epilepsia 32 (1991) 289-293.

[45] T. Nimura, P.R. Weinstein, S.M. Massa, S. Panter, F.R. Sharp, Heme oxygenase-1 (HO-1) protein induction in rat brain following focal ischemia, Mol. Brain Res. 37 (1996) 201-208.

[46] N. Panahian, M. Yoshiura, M.D. Maines, Overexpression of heme oxygenase-1 is neuroprotective in a model of permanent middle cerebral artery occlusion in transgenic mice, J. Neurochem. 72 (1999) 1187-1203.

[47] D.A. Parsell, S. Lindquist, The function of heat-shock proteins as molecular chaperones in stress tolerance: degradation and reactivation of damaged proteins, Annu. Rev. Genet. 27 (1993) 437-496.

[48] J.C. Plumier, J.N. Armstrong, N.I. Wood, J.M. Babity, T.C. Hamilton, A.J. Hunter, H.A. Robertson, R.W. Currie, Differential expression of c-fos, Hsp70 and Hsp27 after photothrombotic injury in the rat brain, Mol. Brain Res. 45 (1997) 239-246.

[49] J.C. Plumier, J.C. David, H.A. Robertson, R.W. Currie, Cortical application of potassium chloride induces the low-molecular weight heat shock protein (Hsp27) in astrocytes, J. Cereb. Blood Flow Metab. 17 (1997) 781-790.

[50] J.C. Plumier, J.N. Armstrong, J. Landry, J.M. Babity, H.A. Robert- 
son, R.W. Currie, Expression of the 27,000 mol. wt heat shock protein following kainic acid-induced status epilepticus in the rat, Neuroscience 75 (1996) 849-856.

[51] A. Reichenbach, A. Siegel, M. Rickmann, J.R. Wolff, D. Noone, S.R. Robinson, Distribution of Bergmann glial somata and processes: implications for function, J. Brain Res. 36 (1995) 509-517.

[52] R. Robitaille, Modulation of synaptic efficacy and synaptic depression by glial cells at the frog neuromuscular junction, Neuron 21 (1998) 847-855.

[53] G. Rordorf, W.J. Koroshetz, J.V. Bonventre, Heat shock protects cultured neurons from glutamate toxicity, Neuron 7 (1991) 10431051.

[54] F.R. Sharp, S.M. Massa, R.A. Swanson, Heat-shock protein protection, Trends Neurosci. 22 (1999) 97-99.

[55] R.A. Sheller, M.E. Smyers, R.M. Grossfeld, M.L. Ballinger, G.D. Bittner, Heat-shock proteins in axoplasm: High constitutive levels and transfer of inducible isoforms from glia, J. Comp. Neurol. 396 (1998) $1-11$.

[56] T. Shinomura, S. Nakao, K. Mori, Reduction of depolarization-induced glutamate release by heme oxygenase inhibitor: possible role of carbon monoxide in synaptic transmission, Neurosci. Lett. 166 (1994) 131-134.

[57] S.H. Snyder, S.R. Jaffrey, R. Zakhary, Nitric oxide and carbon monoxide: parallel roles as neural messengers, Brain Res. Rev. 26 (1998) 167-175.

[58] R.M. Tanguay, Y. Wu, E.W. Khandjian, Tissue-specific expression of heat shock proteins of the mouse in the absence of stress, Dev. Genet. 14 (1993) 112-118.

[59] S. Takizawa, H. Hirabayashi, K. Matsushima, K. Tokuoka, Y. Shinohara, Induction of heme oxygenase protein protects neurons in cortex and striatum, but not in hippocampus, against transient forebrain ischemia, J. Cereb. Blood Flow. Metab. 18 (1998) 559-569.
[60] M. Tytell, M.F. Barbe, I.R. Brown, Stress (heat shock) protein accumulation in the central nervous system: its relationship to cell stress and damage, in: F.J. Seil (Ed.), Advances in Neurology, Vol. 59, Raven Press, New York, 1993, pp. 292-303.

[61] M. Tytell, S.G. Greenberg, R.J. Lasek, Heat shock-like protein is transferred from glial to axon, Brain Res. 363 (1986) 161-164.

[62] A. Verma, D.J. Hirch, C.E. Glatt, G.V. Ronnett, S.H. Snyder, Carbon monoxide: a putative neural messenger, Science 259 (1993) $381-384$

[63] S. Vibulsreth, F. Hefti, M.D. Ginsberg, W.D. Dietrich, R. Busto, Astrocytes protect cultured neurons from degeneration induced by anoxia, Brain Res. 422 (1987) 303-311.

[64] P.J. Voisin, S. Pardue, F. Macouillard, G. Yehia, J. Labouesse, M. Morrison-Bogorad, Differential expression of heat shock 70 proteins in primary cultures from rat cerebellum, Brain Res. 739 (1996) $215-234$.

[65] K. Wu, J.L. Xu, P.C. Suen, Y.Y. Huang, H.T. Mount, Nitric oxide increases calcium/calmodulin-dependent phosphorylation of proteins in the postsynaptic density of adult rat cerebral cortex, Mol. Brain Res. 40 (1996) 22-26.

[66] S. Wyatt, C. Mailhos, D.S. Latchman, Trigeminal ganglion neurons are protected by the heat shock proteins Hsp70 and Hsp90 from thermal stress but not from programmed cell death following nerve growth factor withdrawal, Mol. Brain Res. 39 (1996) 52-56.

[67] M.A. Yenari, S.L. Fink, G. Hua Sun, L.K. Chang, M.K. Patel, D.M. Kunis, D. Onley, D.Y. Ho, R.M. Sapolsky, G.K. Steinburg, Gene therapy with Hsp72 is neuroprotective in rat models of stroke and epilepsy, Ann. Neurol. 44 (1998) 584-591.

[68] T. Yoshida, M. Sato, Posttranslational and direct integration of heme oxygenase into microsomes, Biochem. Biophys. Res. Commun. 163 (1989) 1086-1092. 